\title{
Characterization of early transcriptional responses to cadmium in the root and leaf of Cd-resistant Salix matsudana Koidz
}

Jingli Yang ${ }^{1}$, Kun Li ${ }^{2}$, Wei Zheng ${ }^{3}$, Haizhen Zhang ${ }^{1}$, Xudong Cao ${ }^{2}$, Yunxiang Lan ${ }^{2}$, Chuanping Yang ${ }^{1 *}$ and Chenghao $\mathrm{Li}^{1 *}$

\begin{abstract}
Background: Salix matsudana Koidz. is a fast growing tree species. It has a high cadmium (Cd) tolerance capacity, making it potentially suitable for phytoremediation. Presently, transcriptomic and physiological $\mathrm{Cd}$ response mechanisms are poorly understood. Transcriptomic analysis in early response to high (50 $\mu \mathrm{M}) \mathrm{Cd}$ levels was investigated in leaf and root of Cd-resistant S. matsudana Koidz.

Results: Analysis of the response profiles demonstrate the existence of a complex transcriptional network in the root and leaf when exposed to $\mathrm{Cd}$. The main response in the root involved up-regulation of genes associated with defence response via callose deposition in the cell wall and cell wall thickening. In the leaf, transcripts related to biotic stress signalling and secondary metabolism were activated. Additionally, many lignin and brassinosteroids synthesis pathway genes were induced mainly in the leaf, indicating that gene response to $\mathrm{Cd}$ was tissue-specific. The $\mathrm{Cd}$ transcriptome results were consistent with observed physiological changes.

Conclusion: The sub-localization, transcriptional network, and physiological regulation demonstrate the tissue-specific manner of $\mathrm{Cd}$ response, and provide a novel insight into in early response of tree species to $\mathrm{Cd}$ exposure.
\end{abstract}

Keywords: Salix matsudana Koidz, Cadmium, Brassinosteroids, Transcriptome

\section{Background}

Cadmium $(\mathrm{Cd})$ is one of the most toxic nonessential elements for plants. Accumulation of $\mathrm{Cd}$ into the food chain via crop root absorption from soil environment is a threaten to human health. This makes it necessary to clean-up Cd contaminated soils. A promising remediation technologies is phytoremediation, the use of plants to clean up polluted soils [1]. Suitable plants for phytoremediation should possess multiple traits such as fast growth, high biomass production, easy harvest and high accumulation of a range of heavy metals in their harvestable parts [2]. Willow is a fast growing, productive and deeply rooted tree, well adapted to temperate region climatic conditions, tolerated temporary water-logging [3]. Recent research has shown that willow has considerable

\footnotetext{
* Correspondence: yangcp@nefu.edu.cn; chli0@163.com

${ }^{1}$ State Key Laboratory of Forest Genetics and Tree Breeding, Northeast

Forestry University, 26 Hexing Road, Harbin 150040, China

Full list of author information is available at the end of the article
}

potential for the phytoremediation of heavy metal contaminated land and has the capacity to accumulate elevated levels of $\mathrm{Cd}$ in aboveground biomass compartments $[4,5]$. Among various clones, Salix matsudana Koidz. is a Chinese willow species belonging to the Salicaceae family, and is native to northeastern China. It has been reported that some clones of $S$. matsudana have high heavy metal tolerance [6].

The molecular mechanisms underlying the adaptation to metals in herbaceous model plants are well studied. Phytochelatins (PCs) and glutathione (GSH) can bind $\mathrm{Cd}$ iron forming cd-ligands and were transported to vacuoles [7]. It is reported that metallothioneins (MTs) and PCs work cooperatively to protect Arabidopsis thaliana from $\mathrm{Cu}$ and $\mathrm{Cd}$ toxicity [8]. $\mathrm{Cd}$ can enter the plant symplast through ZIP transporters [9]. Additionally, heavy metal ATPase (HMA) plays a key role in cellular metal efflux [10-12]. Generally, Cd stress finally activates antioxidative enzymes responsive. However, trees 
could have evolved also distinct mechanisms to cope with elevated metal concentrations. Their elucidation requires broad scale transcriptional, proteomic and metabolic approaches. The high-throughput next generation sequencing (NGS) technology such as RNA-seq and Digital Gene Expression (DGE) is an efficient method to illustrate the mechanisms at molecular level. Compared with traditional gene cloning, NGS technology has characteristics with high efficiency, fast run times and high accuracy $[13,14]$. Among the different types of NGS technology, the Illumina Hiseq system has been widely used $[15,16]$, owing to its high throughput, accuracy, and low costs. Up to date, only a few study on transcriptome sequensing are available for willow [17-19]. However, the transcriptional responses of Salix to Cd contamination remain unknown. This study investigated the early transcriptional response to a high $\mathrm{Cd}(50 \mu \mathrm{M})$ treatment for $10 \mathrm{~h}$ in the root and leaves of S. matsudana plants by de novo transcriptome analysis. The identified molecular and physiological mechanisms provide a novel insight into $\mathrm{Cd}$ tolerance in tree species, and play a foundational role in phytoremediation investigations.

\section{Methods}

\section{Plant material and cadmium exposure}

Open-pollinated mature seeds of S. matsudana Koidz. var. matsudana were collected during late May from 60 -year-old trees grown on the campus of Northeast Forestry University, Harbin, China. Seeds were stored and sterilized as described by Yang et al. [20], and inoculated on 1/2 MS medium [21] supplemented with $150 \mu \mathrm{M} \mathrm{Cd}\left(\mathrm{CdCl}_{2}\right)$, without plant growth regulators (PGRs), for 1 month (Additional file 1: Figure S1a). Cd resistant seedlings were then cultured in the same medium without $\mathrm{Cd}$ at successive 4 -week intervals. When regenerated seedlings reached a height of $5 \mathrm{~cm}$, the materials were cultured in 1/2 MS medium containing $50 \mu \mathrm{M} \mathrm{Cd}$. Before this, we treated S. matsudana with different concentration of $\mathrm{Cd}, 50 \mu \mathrm{M}$ is the highest concentration that neither affect the phenotype nor the growth, thus chose this concentration. To determine mechanisms in which cadmium accumulation altered molecular functioning in tissues at an early stage $(10 \mathrm{~h})$, three independent individual of leaves and roots were respectively collected and pooled into one sample to be sequenced using Illumina paired-end sequencing technology for de novo transcriptomic analysis. Non-treated materials were used as control.

Media used in experiments were adjusted to $\mathrm{pH} 5.8$ before adding $0.8 \%$ Plant agar (Duchefa, The Netherland), and then sterilized by autoclaving at $1.1 \mathrm{~kg} \mathrm{~cm}^{-2}$ $\left(121{ }^{\circ} \mathrm{C}\right)$ for $15 \mathrm{~min}$. The cultures were incubated under a $16 \mathrm{~h}$ light $/ 8 \mathrm{~h}$ dark photoperiod at $25{ }^{\circ} \mathrm{C}$ under illumination at $45 \mu \mathrm{mol} \mathrm{m} \mathrm{m}^{-2} \mathrm{~s}^{-1}$ with cool white fluorescent lights.

\section{cDNA library preparation and sequencing}

Total RNA was extracted using the hexadecyltrimethylammonium bromide (CTAB) method [22], and digested with RNase-free DNase I (Promega, Madison, USA) at $37{ }^{\circ} \mathrm{C}$ for $30 \mathrm{~min}$. The concentration and integrity of RNA samples for transcriptome analysis were evaluated using a NanoPhotometer (GmbH, Munich, Germany). The quality and quantified of extracted RNA was assessed using an Agilent 2100 Bioanalyzer (Agilent Technologies, Mississauga, Canada) with an RNA integration number (RIN) of 8, which is an algorithm for assigning integrity values to RNA measurements. For transcriptome analysis, the cDNA library was prepared using the TruSeq Sample Preparation Kit (Illumina, San Diego, CA, USA) following the manufacturer's instructions. The samples were listed as following (Table 1) and clustered in flow cells to construct the cDNA library to be sequenced by the Illumina HiSeqTM 2000.

The sequencing data from this study were deposited in the NCBI Sequence Read Archive (SRA, http://www. ncbi.nlm.nih.gov/Traces/sra/) under accession number SRR1167984.

\section{De novo assembly, annotation and MapMan analysis}

Clean reads were obtained by deleting empty reads, adaptor sequences, and low-quality sequences. The clean reads were assembled into contigs using Trinity [23], and the contigs were connected using Unigene. For functional annotation, the de novo transcriptomic target sequences were used to blast against the Phytozome Populus trichocarpa version 2.2 transcript database. BlastX alignment $\left(E\right.$-value $\left.<10^{-5}\right)$ was performed between unigenes and the following protein databases: NCBI non-redundant protein (nr) (http://www.ncbi.nlm. nih.gov/), Swiss-Prot (http://www.expasy.org/), KEGG (http://www.genome.jp/kegg), and COG (http://www. ncbi.nlm.nih.gov/COG). The highest sequence similarity to a gene in the NCBI Nr database was annotated to the Unigene. Gene Ontology (GO) annotations for the Unigenes were determined by Blast2GO [24], and WEGO software [25] was used to analyze GO functional classifications for all Unigenes.

To categorize differentially expressed genes according to their biological functions, the closest Arabidopsis homolog (Arabidopsis gene identifiers, AGIs) of a $S$. matsudana gene was determined was determined by a translated nucleotide BLAST (BLASTx) of the coding sequence of the best $P$. trichocarpa hit against the Arabidopsis protein sequence data set. Annotations were taken from the latest release of The Arabidopsis Information Resource genome, TAIR10.0. Differentially expressed genes 
Table 1 Description of libraries for the sequence running

\begin{tabular}{llcccc}
\hline Sample name & Insert size $(\mathrm{nt})$ & Quality $(\mathrm{ng} / \mu \mathrm{l})$ & Concentration $(\mathrm{nM})$ & Standard QPCR concentration $(\mathrm{nM})$ & Total volume $(\mu \mathrm{l})$ \\
\hline Con_leaf & 211 & 8.98 & 40.63 & 84.92 & 2.47 \\
Cd_leaf & 203 & 9.66 & 44.73 & 74.15 & 2.83 \\
Con_root & 217 & 8.72 & 38.8 & 71.07 & 2.95 \\
Cd_root & 234 & 8.58 & 36.32 & 66.51 & 3.16 \\
\hline
\end{tabular}

were submitted to MapMan v3.5.1 (http://gabi.rzpd.de/ projects/MapMan/) [26] for coexpression analysis as described by Wei et al. [27].

\section{Evaluation of the libraries}

Rigorous algorithms were developed to identify differentially expressed genes between two samples. The correlation of the detected count numbers between parallel libraries was assessed statistically by calculating the Pearson correlation. $P \leq 0.01$, FDR $\leq 0.1$, and the absolute value of $\log 2$ Ratio $\geq 1$ were used as threshold to assess the significance of gene expression difference. For pathway enrichment analysis, we mapped all differentially expressed genes to terms in KEGG database and looked for significantly enriched KEGG terms compared to the genome background.

\section{Quantitative real time polymerase chain reaction (qRT-PCR) analysis}

Total RNA was extracted from Cd-treated and nontreated leaf and root tissue of $S$. matsudana plants using the CTAB method [22], respectively. First-strand cDNA synthesized with $0.5 \mu \mathrm{g}$ purified RNA was reversetranscribed with a Reverse Transcriptase kit (TaKaRa Biotech, Dalian, China). PCR reaction was performed in a volume of $20 \mu \mathrm{l}$, containing $10 \mu \mathrm{l}$ of SYBR premix ExTaq (TaKaRa Biotech, Dalian,China), $0.5 \mu \mathrm{M}$ of forward and reverse primers, and $2 \mu \mathrm{l}$ cDNA template (equivalent to $0.05 \mu \mathrm{g}$ of total RNA). Thermal cycling conditions was performed as following: $10 \mathrm{~s}$ at $95{ }^{\circ} \mathrm{C}$ followed by 40 cycles of $5 \mathrm{~s}$ at $95{ }^{\circ} \mathrm{C}, 30 \mathrm{~s}$ at $60{ }^{\circ} \mathrm{C}$, and $1 \mathrm{~s}$ at $78{ }^{\circ} \mathrm{C}$ for plate reading. The primer sequences of $\beta$-tubulin and 18 randomly selected genes of leaves are given in the Additional file 2: Table S1.

\section{Chlorophyll content of leaf tissues}

Fresh leaf tissue $(1 \mathrm{~g})$ of plant was exposed to $50 \mu \mathrm{M} \mathrm{Cd}$ for $10 \mathrm{~h}$ and collected to determine chlorophyll content. These samples were soaked in $80 \%$-acetone solution ( $5 \mathrm{~mL}$ ) and kept in the dark at $4{ }^{\circ} \mathrm{C}$ for $24 \mathrm{~h}$. The supernatant was collected for analysis in a spectrophotometer (722S, Shanghai Lengguang Technology Co., Ltd, China). Optical densities were recorded at $663 \mathrm{~nm}$ and $645 \mathrm{~nm}$ to determine the concentrations ( $\mu \mathrm{g} \mathrm{g}^{-1}$ fresh mass) of chlorophyll a and chlorophyll b, respectively, and of total chlorophyll $(\mathrm{a}+\mathrm{b})$ in each sample. Non-treated plant was used as control. Each experimental unit was consisted of 10 explants with three replicates.

\section{Analysis of cadmium content}

Roots, stems and leaves of S. matsudana treated with $50 \mu \mathrm{M} \mathrm{Cd}$ for $10 \mathrm{~h}$ or 1 month were dried at $80^{\circ} \mathrm{C}$ until to a constant weight. Samples (0.1-0.2 g) were then dissolved in a mixture of concentrated $\mathrm{HNO}_{3}-\mathrm{HClO}_{4}$ $(5: 1, \mathrm{v} / \mathrm{v})$ and heated at $160{ }^{\circ} \mathrm{C}$ for $5 \mathrm{~h}$. Following cooling, the extract was filtered, and the beaker washed with $3 \mathrm{ml} 6 \mathrm{M} \mathrm{HCl}$. Following treatment, aliquots were obtained to analyse residual $\mathrm{Cd}$ content in the tissues using an atomic absorption spectrophotometer (Atomic Absorption Spectrometer, TAS-986). Non-treated samples were used as the control.

\section{TEM observation}

Leaves and root segments (approximately 2-3 mm long) of plant treated with $50 \mu \mathrm{M}$ Cd for 1 month were collected, and fixed in $2.5 \%$ glutaraldehyde for 2 days. They were then vacuumed at room temperature, washed with PBS ( $\mathrm{pH}=6.8$ ) buffer for 15 min three times, and then fixed with $\mathrm{OsO}_{4}$ for 3-4 h. Samples were dehydrated through an ethanol series, and embedded in Spurr's epoxy resin. Ultrathin sections were obtained using a Power Tome XL ultramicrotome (RMC-Boeckeler Instruments, Tucson, AZ, USA), collected on copper-supported grids, and observed using an H-7650 transmission electron microscope (TEM, Hitachi High-Technologies, Tokyo, Japan).

\section{Callose detection}

Plant materials were cultured in 1/2 MS medium supplemented with $50 \mu \mathrm{M}$ Cd for 2 weeks. Root and leaf callose were detected using aniline blue (Sigma-Aldrich, St. Louis, MO, USA) and observed under a light microscope (Olympus SZ61, Tokyo, Japan).

\section{Histochemical staining of cadmium}

Cadmium localization was performed as described by He et al. [28]. Briefly, sections of root and leaf of $50 \mu \mathrm{M}$ $\mathrm{Cd}$ treated for $10 \mathrm{~h}$ and non-treated plants were soaked in a staining solution containing $30 \mathrm{mg}$ diphenylthiocarbazone dissolved in $60 \mathrm{~mL}$ acetone, $20 \mathrm{~mL}$ water, and $100 \mathrm{~mL}$ glacial acetic acid for $1 \mathrm{~h}$, and then rinsed in deionized water. The prepared section or samples were 
photographed under a light microscope (Olympus SZ61, Tokyo, Japan).

\section{Brassinosteroids inhibition assay}

For plant growth investigation, seedlings cultured in $1 / 2$ MS medium with the addition of $50 \mu \mathrm{M} \mathrm{Cd}$ via cutting propagation were subjected to the following treatment conditions: (1) Non-treatment. (2) $50 \mu \mathrm{M} \mathrm{Cd}$. (3) $10 \mathrm{nM}$ brassinazole (Brz, a specific inhibitor of brassinosteroid (BR) biosynthesis) (4) $50 \mu \mathrm{M} \mathrm{Cd}+10 \mathrm{nM}$ brassinazole. (5) $50 \mu \mathrm{M} \mathrm{Cd}+20 \mathrm{nM}$ Brz. (6) $50 \mu \mathrm{M} \mathrm{Cd}+50 \mathrm{nM} \mathrm{Brz;}$ all treatments were performed for 2 weeks. Non-treated seedlings were used as a control.

\section{Detection of ROS and determination of superoxide} dismutase, catalase, and ascorbate peroxidase activity The quantity of $\mathrm{O}_{2}{ }^{-}$and $\mathrm{H}_{2} \mathrm{O}_{2}$ in leaves and roots of plant treated with $50 \mu \mathrm{m} \mathrm{Cd}$ for $10 \mathrm{~h}$ was monitored by incubation with $2 \mathrm{mM}$ nitroblue tetrazolium (NBT; N6876, Sigma, St. Louis, MO, USA) in $20 \mathrm{mM}$ phosphate buffer ( $\mathrm{pH}$ 6.1) containing $10 \mathrm{mM} \mathrm{NaN}_{3}$, or in 3,3' diaminobenzidine (DAB; D5637, Sigma-Aldrich) ( $\mathrm{pH}$ 3.8), respectively. Chlorophyll was destained by boiling in alcohol $(95 \%, \mathrm{v} / \mathrm{v})$ for $1 \mathrm{~h}$ as described by $\mathrm{Xu}$ et al. [29].

Leaf tissues $(0.5 \mathrm{~g})$ from Cd-treated $(50 \mu \mathrm{M} \mathrm{Cd}$ for $10 \mathrm{~h}$ ) and non-treated plants were ground to a powder in liquid nitrogen. Superoxide dismutase (SOD), catalase (CAT), and ascorbate peroxidase (APX) activities were measured as described previously [30].

\section{Statistical analysis}

All experiments were repeated independently for at least three replicates. Statistical analyses were carried out using SPSS 16.0 for Windows (SPSS Inc., Chicago, IL, USA). Data were compared using Student's $t$ test. Differences were considered to be significant if $P<0.05$.

\section{Results}

\section{Plant growth}

For Cd-resisitant S. matsudana selection, only five seedlings showed relatively vigorous growth from approximately 2000 seeds screened, but their following growth was delayed. After successive culture on medium without $\mathrm{Cd}$, the seedlings were screened on medium supplemented with $50 \mu \mathrm{M}$ Cd for 1 month. Under Cd treatment conditions, the number of root was higher in $\mathrm{Cd}$ resistant lines (Additional file 1: Figure S1b, right) than in nonresistant lines (Additional file 1: Figure S1b, left), and leaves of $\mathrm{Cd}$ resistant lines remained green (Additional file 1: Figure S1b, right), whereas leaves of control check (CK) plants withered and yellowed (Additional file 1: Figure $\mathrm{S} 1 \mathrm{~b}$, left). One of the Cd-resistant plant lines was selected for the following analyses.

\section{Chlorophyll content and cadmium accumulation}

Chlorophyll a, b, and $\mathrm{a}+\mathrm{b}$ content was reduced in the Cd-treated plant compared with non-treated plants (Additional file 1: Figure S2a). The Cd distribution pattern was then investigated when exposed to $\mathrm{Cd}$ for 1 month (Additional file 1: Figure S2b), the highest $\mathrm{Cd}$ concentration was found in the roots, and it was lower in the stem and leaf. The Cd concentrations in the analysed tissues were 852.77 (root), 197.96 (stem), and 65.98 (leaf) $\mu \mathrm{g} \mathrm{g}^{-1}$ dry weight, thus confirming hyperaccumulation. Cd was not observed in control plant tissues (Additional file 1: Figure S2b).

TEM results revealed that the cortical cells of nontreated roots were not organized (Fig. 1a). No Cd was detected in the cells (Fig. 1b) or intercellular space (Fig. 1c). The shape of root cells changed following $50 \mu \mathrm{M}$ Cd treatment for 1 month, illustrating that $\mathrm{Cd}$ damaged plant development. The cortical cells were smaller and neater, with observable cell wall thickening (Fig. 1d). There were some $\mathrm{Cd}$ deposits in the vacuole (Fig. 1e) and intercellular space (Fig. 1f). But no considerably differences in leaves between treated and nontreated samples (data not shown).

\section{Cadmium localization in cortical root cells}

$\mathrm{Cd}$ concentration was measured in various tissues in the early response to $\mathrm{Cd}$ (for $10 \mathrm{~h}$ ). The results revealed that only a small amount of $\mathrm{Cd}(35 \mu \mathrm{g} / \mathrm{g}$. FW) had accumulated in the root at this point (Fig. 2a), indicating that root-to-shoot translocation does not exist at this early stage. Histochemical staining for $\mathrm{Cd}$ was conducted to investigate cellular localization of $\mathrm{Cd}$ in tissues at this stage (Fig. 2b-e). A large difference was detected between non- and Cd-treated $(50 \mu \mathrm{M})$ roots. Greater darkbrown staining was observed in the $\mathrm{Cd}$-treated root (Fig. 2c) compared with the non-treated sample (Fig. 2b). From the root cross section, it was observed that cadmium-dithizone staining was mainly detected in cortical cells (Fig. 2e); staining was not detected in the control plant (Fig. 2d). It is noteworthy that there was no difference between control (Fig. 2f) and Cd-treated plant leaves (Fig. 2g).

\section{Illumina sequencing and de novo assembly}

Because of the absence of reference genomic sequences, de novo assembly was applied to construct transcripts from RNA-seq reads.

Following cleaning of data, high quality reads were obtained for control and Cd-treated leaf and root samples (Additional file 2: Table S2). Following assembling, high quality reads were assembled to contigs, and further assembled to unigenes (Additional file 2: Table S3). 


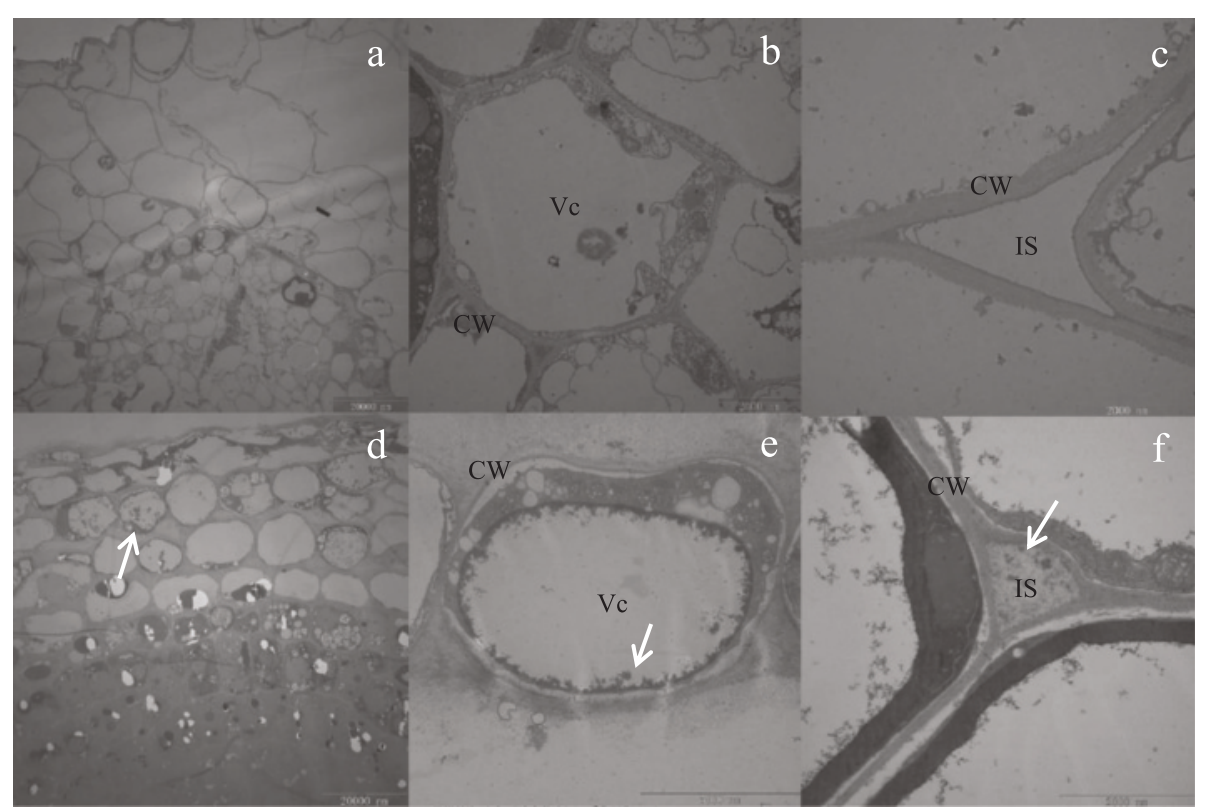

Fig. 1 Transmission electron microscope observation of Salix matsudana Koidz. root cell. a Cross section of a non-treated plant root. b Single cell of a non-treated plant root. c Intercellular space of a non-treated plant root. $\mathbf{d}$ Cross section of a Cd-treated plant root. e Single cell of a Cd-treated plant root. $\mathbf{f}$ Intercellular space of a Cd-treated plant root. CW Cell wall, Vc Vacuole, IS Intercellular space. The arrows stand for Cd deposits

\section{Functional annotation}

A sequence similarity search was conducted against the NCBI Nr database. In the Nr classifications, 66.2 and $78.3 \%$ of mapped unigenes showed significant homology (Additional file 1: Figure S3a and b). Numerous unigenes (85.2\%) showed homology with poplar (Populus trichocarpa; Additional file 1: Figure S3c).

Unigenes were searched against the COG database for functional prediction and classification. Total 29,894 sequences were assigned to COG classifications (Additional file 2: Table S4, Additional file 1: Figure S3d). Among the 24 COG categories, the cluster for general function prediction only $(17.1 \%)$ was the largest group, followed by transcription (9.5\%).

Based on Nr annotations, 316,118 unigenes were assigned gene ontology (GO) terms, there were 37,909 functional terms. Among the three major GO classifications, annotated unigenes assigned to cellular biological processes made up the largest set $(156,617,49.5 \%)$, followed by cellular components $(113,307,35.8 \%)$, and molecular function (46,194, 14.6 \%) (Additional file 2: Table S5, Additional file 1: Figure S3e). The functionally assigned unigenes covered a comprehensive range of GO categories.

\section{Comparison of leaf and root in response to cadmium using MapMan}

After exposure to $50 \mu \mathrm{M} \mathrm{Cd}$ for $10 \mathrm{~h}, 912$ genes were determined to be up-regulated and 669 down-regulated in the leaf, while 448 genes were up-regulated and 459 genes down-regulated in the root. To gain further insight into the coexpression of functional gene response to $\mathrm{Cd}$, the unique AGIs were selected in S. matsudana. In all, 447 homologs were identified in the leaf (Additional file 2: Table S6) and 145 homologs (Additional file 2: Table S7) in the root, these were further analysed in MapMan.

MapMan analysis revealed that almost all genes identified as being up-regulated under biotic stress and involved in metabolism were present in both the leaf and root (Fig. 3). More Cd-responsive genes were identified in the leaf than in the root, suggesting that different mechanisms exist at the molecular level in the leaf and root for dealing with conditions of $\mathrm{Cd}$ stress. Among the Cd-responsive genes, numerous genes involved in biotic stress signalling were activated, there included heat shock proteins (HSPs), glutathione S-transferase gene (GST), and glutathione (GSH) in the leaf (Additional file 2: Table S8, Fig. 3a), while most of the HSPs and all GST genes were induced in the root (Additional file 2: Table S9, Fig. 3b). A number of genes related to secondary metabolism and many genes implicated in signalling pathways were also significantly up-regulated in the leaf and root. Additionally, many of the cell wall related genes involved in biotic stress (Fig. 3a and b) and cell wall metabolism were highly expressed (Fig. 3c and d) in both the leaf and root.

\section{Differential expression of genes involved in cell wall} metabolism and lignin synthesis in the leaf and root Many of the differentially expressed genes were upregulated in both the leaf (Fig. 4a, Additional file 2: Table 

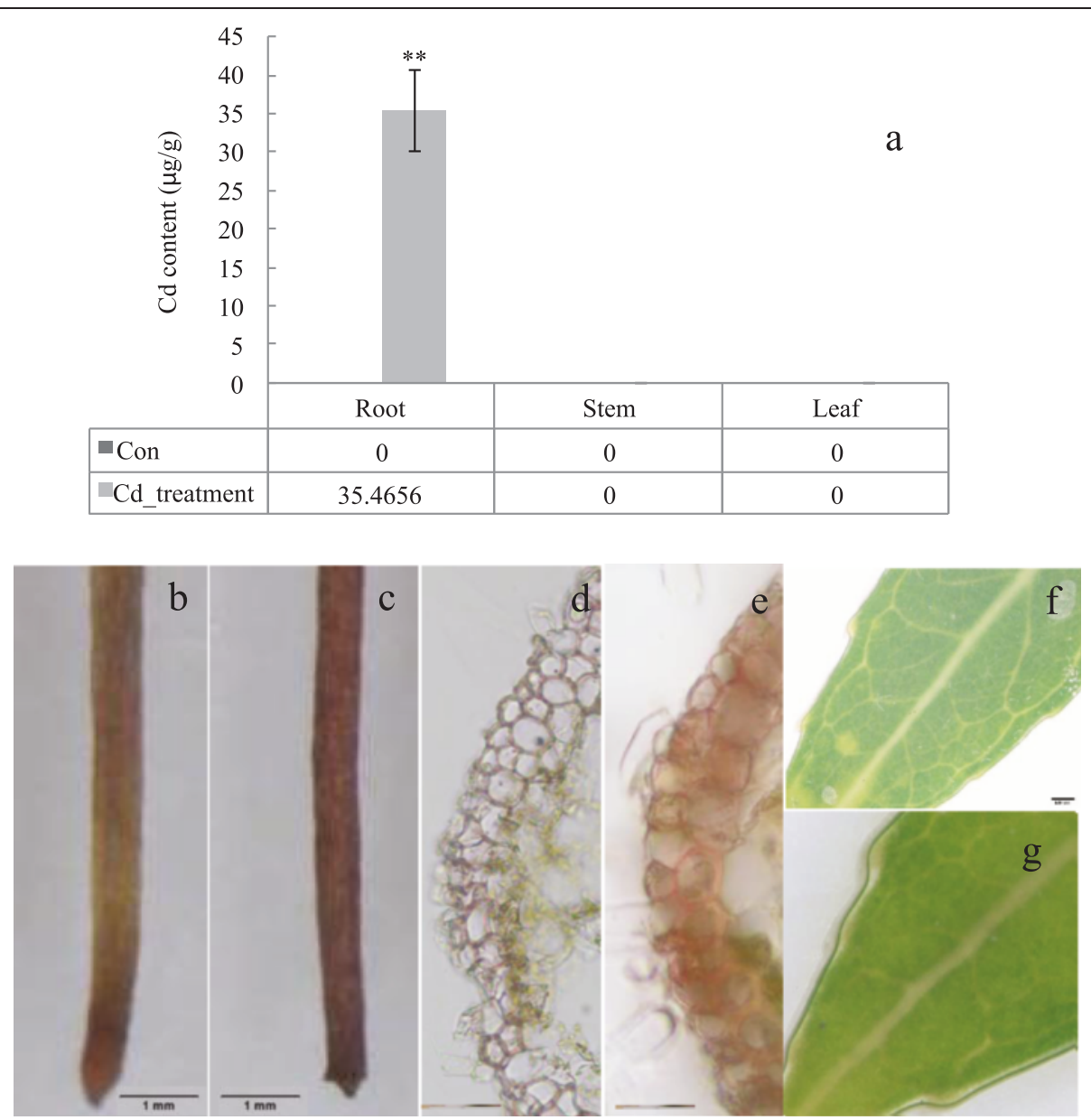

Fig. 2 Cadmium concentration in tissues, and localization in the root of S. matsudana Koidz.. a Cd concentration following $50 \mu \mathrm{M} C \mathrm{Cd}$ treatment for 10 h. b Non- and (c) Cd-treated roots stained with diphenylthiocarbazone solution. $\mathbf{d}$ Cross section of non-treated root stained with diphenylthiocarbazone solution. e Cross section of Cd-treated root stained with diphenylthiocarbazone solution. $\mathbf{f}$ Non- and (g) Cd-treated leaves stained with diphenylthiocarbazone solution. Bar $=1 \mathrm{~mm}$

S10) and root (Fig. 4b, Additional file 2: Table S10) when exposed to $\mathrm{Cd}$. Plants first absorb heavy metals through their root cell wall. Therefore, reducing influx across the cell wall is a key regulation switch. The expression profile of cell wall metabolism related genes were investigated. GO enrichment analysis revealed the expression of all genes involved in the defence response by callose deposition in the cell wall (Fig. 4c, Additional file 2: Table S10) and genes involved in cell wall thickening (Fig. $4 \mathrm{~d}$, Additional file 2: Table S10) were up-regulated in the leaf. Similarly, all genes involved in the defence response by callose deposition in the cell wall (Fig. 4e, Additional file 2: Table S10) and almost all differentially expressed genes involved in cell wall thickening (Fig. 4f, Additional file 2: Table S10) were up-regulated in the root.

Genes coding for phenylalanine ammonia-lyase (PAL), 4-coumarate:coenzyme A ligase (4CL), ferulate-5-Hydro xylase (F5H), Coffee acyl coenzyme A-O-methyl transferase
(CCoAOMT), and Cinnamyl alcohol dehydrogenase (CAD) showed elevated expression in the leaf (Fig. 5), but were not specifically expressed in the root. It is proposed that lignin content is specifically increased in the leaf, but not the root.

Up-regulation of genes involved in sulphate assimilation, flavonoid metabolism and BRs biosynthesis in the leaf

As previously reported, sulphate assimilation and flavonoid metabolism respond to $\mathrm{Cu}$ or $\mathrm{Cd}$ [31]. In this study, numerous differentially expressed genes were involved in sulphate assimilation (Additional file 1: Figure S4) and metabolism of flavonoids (Additional file 1: Figure S5) in the leaf, almost all of these genes were upregulated. In particular, numerous genes involved in BRs biosynthesis were mainly differentially expressed in the leaf, all of these were up-regulated (Fig. 6). 


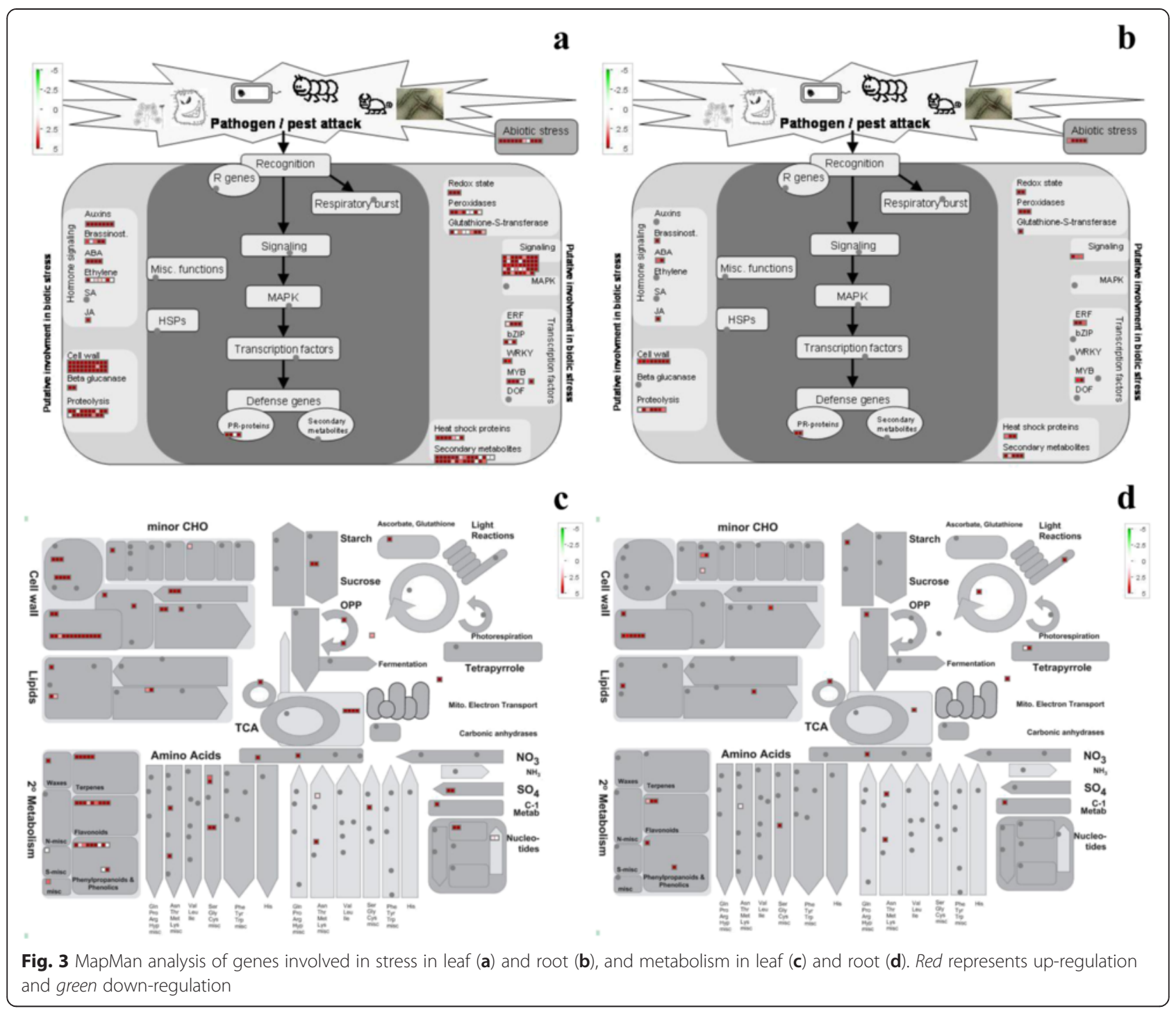

Up-regulation of genes involved in metal transport and chelation binding in the root

ZIP transporters were highly expressed in roots in response to Cd (Additional file 2: Table S9, Fig. 3). Additionally, both sulphate and $\mathrm{ABC}$ transporters showed inducible higher expression levels in the leaf (Additional file 2: Table S8, Fig. 3) and root (Additional file 2: Table S9, Fig. 3). However, the expression levels of some known heavy metal resistant genes, including HMA, PC, and MT remained unchanged.

Down -regulation of genes following cadmium exposure Many genes were down-regulated upon $\mathrm{Cd}$ exposure, including members of the zinc finger family, cellulose synthase genes, and genes encoding arabinogalactan protein, xyloglucan endotransglycosylase and the auxinresponse gene, indole-3-acetic acid (IAA) in the leaf (Additional file 2: Table S11), but only arabinogalactan protein and xyloglucan endotransglycosylase were inhibited in the root (Additional file 2: Table S12). While the gene synthesize IAA, was up-regulated in root (Additional file 2: Table S12).

\section{Validation of transcriptomic data by qRT-PCR}

To validate the RNA-Seq data, 18 of the identified $\mathrm{Cd}$ tolerance related genes were verified by qRT-PCR. A total of 15 genes, including those encoding steroid 22alpha-hydroxylase (DWF4), steroid 5-alpha-reductase (DET2), F5H, CAD, 4CL, sulfite oxidase (SUOX), flavanone 4-reductase (DER), flavonol synthase (FLS), leucoanthocyanidin reductase (LAR), Hsps, sulphate transporter, ABC transporter, ZIF transporter, IAA and GST) were up-regulated, while three genes, encoding CCR, arabinogalactan protein, and xyloglucan endotransglycosylase were down-regulated (Fig. 7). The qRT-PCR based expression profiles of the selected 

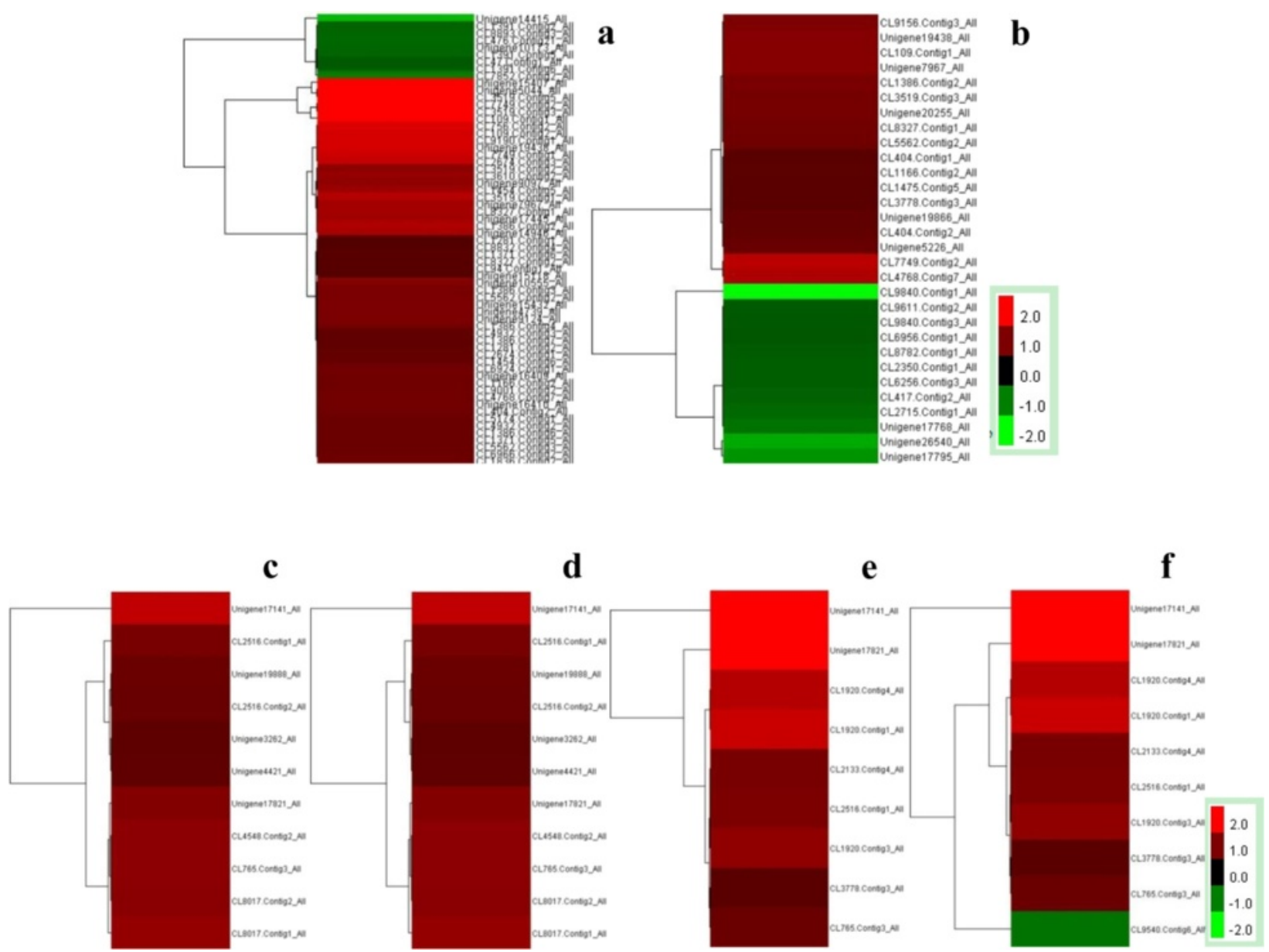

Fig. 4 Genes involved in early response to Cd ions and expression profile of defence response by callose deposition in the cell wall, and cell wall thickening. a Cd-responsive genes in leaf, (b) Cd-responsive genes in root (c) Genes of callose deposition in the cell wall of the leaf. $\mathbf{d}$ Genes of cell wall thickening in the leaf. e Genes of callose deposition in the cell wall of the root. $\mathbf{f}$ Genes of cell wall thickening in the root

genes were similar to that detected using Illuminasequencing based method, and thus supports our results.

\section{The cadmium transcriptome is linked with physiological changes}

Treatment of $S$. matsudana plants with $50 \mu \mathrm{M}$ Cd for 2 weeks resulted in the induction of synthesis and deposition of callose in roots and leaves (Fig. 8). The blue colouring of the root (Fig. 8a, left) and leaf (Fig. 8b, left) in the control was lighter than that observed in the root (Fig. 8a, right) and leaf (Fig. 8b, right) of Cd treated plant.

Plants grown under $50 \mu \mathrm{M} \mathrm{Cd}$ conditions showed similarly to the control plants (Fig. 9a and b) with green leaves observed in both control and $\mathrm{Cd}$ treated plants. Furthermore, the addition of Brz (BR inhibitor) had no significant affect upon plant growth (Fig. 9c). However, when grown under $50 \mu \mathrm{M} \mathrm{Cd}$ conditions, application of different concentrations of Brz affected growth
(Fig. 9d-f). As concentration increased the plants became more sensitive to $\mathrm{Cd}$, with leaves becoming yellow and falling off (Fig. 9f). This assay indicated that BRs directly play a central role in the early response to $\mathrm{Cd}$ in leaves.

In plants, Cd stress markedly induces ROS accumulation and affects antioxidant content [29]. Therefore, the generation of ROS was assayed. Leaves and roots were stained with NBT (a histochemical reagent for superoxide anions; Fig. 10a and b) and DAB (a histochemical reagent for $\mathrm{H}_{2} \mathrm{O}_{2}$; Fig. $10 \mathrm{c}$ and d). However, the ROS level was higher in the leaves and roots of the plants treated with $\mathrm{Cd}$ than that in control plants (Fig. 10a-d). Production of ROS was mainly observed in the root tip and the elongation zone (Fig. 10b and d). SOD, CAT, and APX activities were enhanced in the Cd-treated plant (Fig. 10e-g), indicating that antioxidant activity was activated in the early response to $\mathrm{Cd}$. 


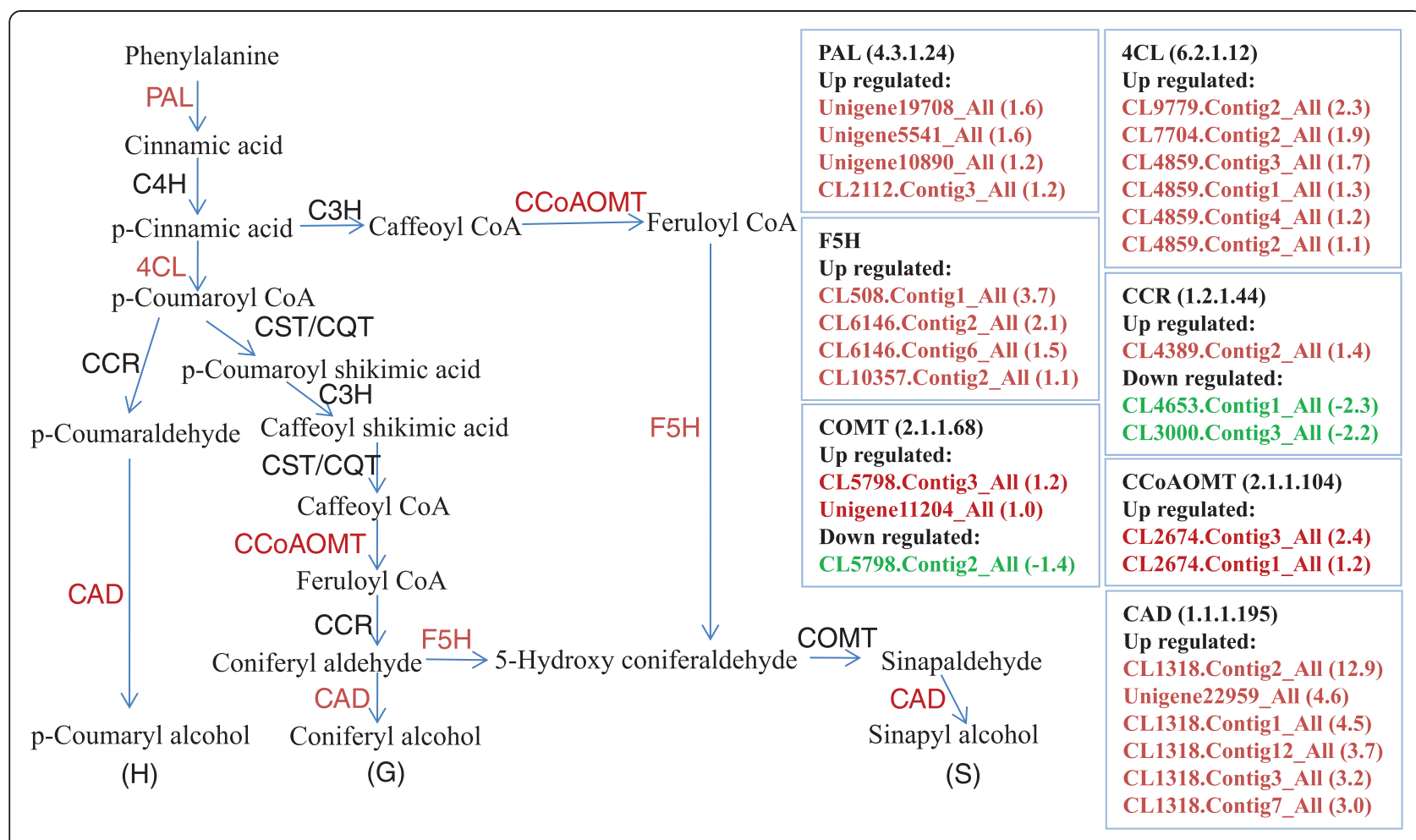

Fig. 5 Biosynthesis pathway of lignin in the S. matsudana leaf after exposure to $50 \mu \mathrm{m} \mathrm{Cd}$ for $10 \mathrm{~h}$

\section{Discussion}

\section{Vacuolar Sequestration in root cell and transcriptionic regeulation in leaf are main mechanisms in early response to $\mathrm{Cd}$}

This study investigated early effects of stress in the leaf and root of $S$. matsudana at high $\mathrm{Cd}$ concentration. Overall, the number of differentially expressed genes in the leaf was greater than in the root, and especially for up-regulated genes (Fig. 3). A large number of differentially regulated genes involving biological regulation and metabolism responses to $\mathrm{Cd}$ were different in the leaf (Fig. 3a and c) and root (Fig. 3b and d), probably owing to the lower $\mathrm{Cd}$ accumulation in the leaf (Fig. 2a). It was observed that some regulated genes or pathways were expressed in tissue-specific manner during the early response to $\mathrm{Cd}(10 \mathrm{~h})$, leading to the development of different $\mathrm{Cd}$ defence mechanisms in the leaf and root.

Concentration analysis revealed that roots accumulated more Cd than other plant tissue (Fig. 2a). The results suggested that $\mathrm{Cd}$ only existed in the roots at an early stage, as $\mathrm{Cd}$ was transported to aboveground parts after 1 month of treatment. Metals are transported from roots to aboveground tissues via the xylem, and localize in aerial tissues; they are often compartmentalized or sequestrated in inactive photosynthetic tissues [32]. Cadmium compartmentalization in the vacuoles is common for herbaceous plants such as Arabidopsis halleri and Thlaspi caerulescens [32], and proven in Populus [29]. In the current study, sequestration in the vacuolar was also a strategy for S. matsudana to minimize cadmium damage.

Currently, no Cd-specific influx transporter has been reported for plant cells, however, transport can be realized by ZIP transporters, albeit at a low affinity; ZIP transporters have a highly specific transport affinity for $\mathrm{Zn}$ or $\mathrm{Fe}$ [33]. In the current study, ZIP transporters were highly expressed in the root (Additional file 2: Table S9, Fig. 3), suggesting that Cd was co-transported into the protoplast. PCs and glutathione (GSH)-derived metal-binding peptides are produced upon sulphate assimilation and are involved in metal detoxification; they are recognized as substrates and transported into the vacuole [9]. Generally, $\mathrm{Cd}$ is transported into the vacuolar in the form of a PC-Cd complex by ATP-binding cassette $(\mathrm{ABC})$ transporters, and not as an independent $\mathrm{Cd}$ ion $[34,35]$. GSH and $\mathrm{ABC}$ transporter genes were predominantly expressed (Tables S8 and S9, Fig. 3). In fact, the TEM result confirmed that Cd was segregated into the vacuole (Fig. 1e). We therefore speculate that it realize vacuole sequestration in $S$. matsudana by other pathways.

\section{Cell wall metabolism and lignin synthesis play a central role in early response to $\mathrm{Cd}$}

The cell wall is the first plant structure to come in contact with metals, and binding metal to the plant cell wall 
BRASSINOSTEROID BIOSYNTHESIS

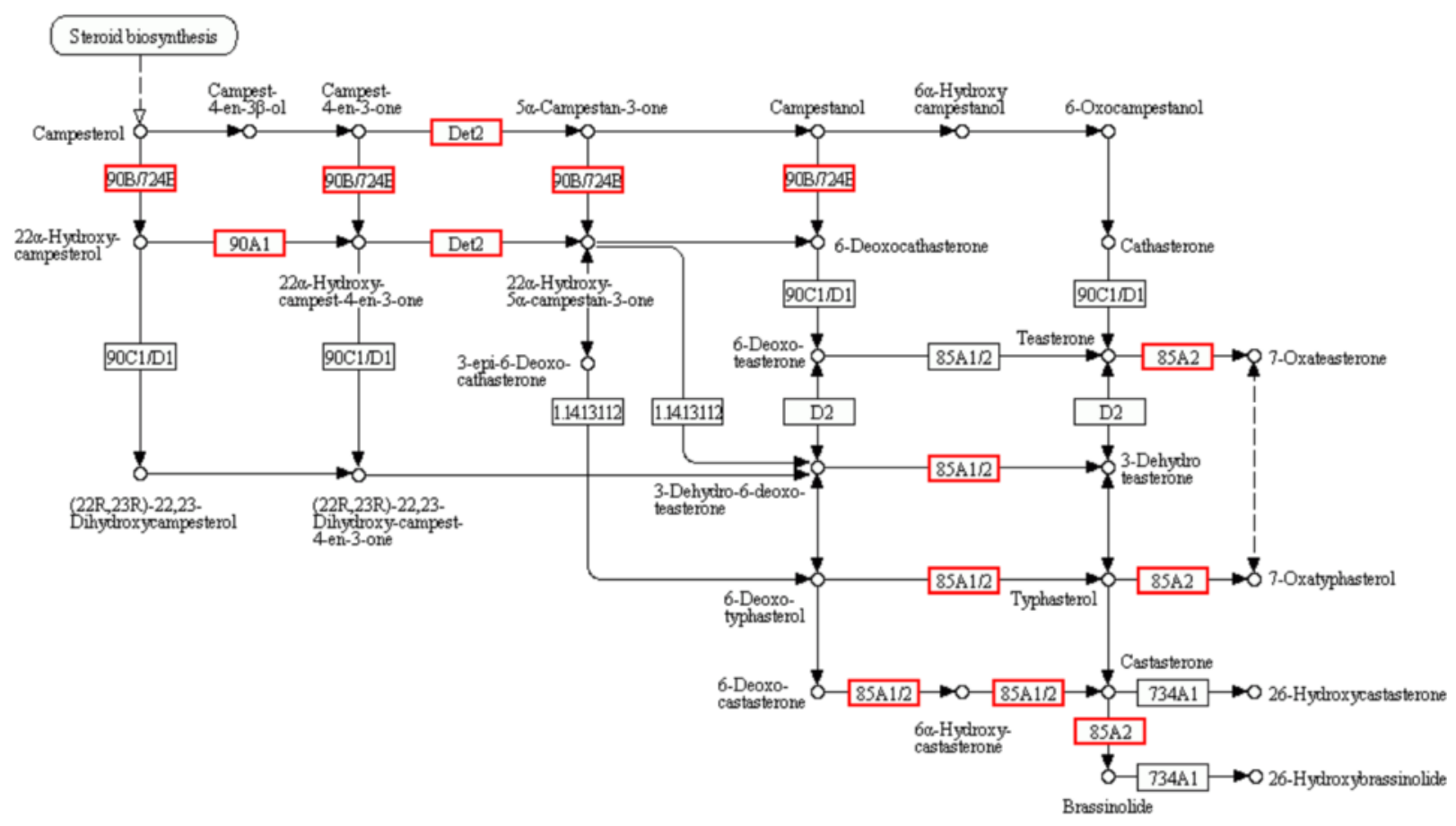

$009056 / 11112$

(c) Kanehisa Laboratonies

Fig. 6 Metabolism pathways of brassinosteroid biosynthesis after exposure to $50 \mu \mathrm{m} C \mathrm{~d}$ for $10 \mathrm{~h}$

is a method of preventing metal entry into plants [36]. We observed root cell wall thickening following plant exposure to $50 \mu \mathrm{M} \mathrm{Cd}$ for 1 month (Fig. 1d). Furthermore, in the treated plants, granular deposits were observed in the intercellular space in the cortical part of the root (Fig. 1f); this phenomenon did not occur in the control plants (Fig. 1a and c).

Cell wall component polysaccharides can bind divalent and trivalent metal ions [37]. Callose (a polysaccharide) deposition in adjacent cell walls may effectively block symplastic transport of metal ions through the plasmodesmata [38]. This may protect the plant from a wide spread of toxic metal ions. Although the precise role of the induction of callose synthesis in plants exposed to toxic metal ions remains unclear, it is reported that the callose produced likely functions as a physical barrier to inhibit transport of metal ions from the apoplast to the symplast [39]. Increased callose synthesis

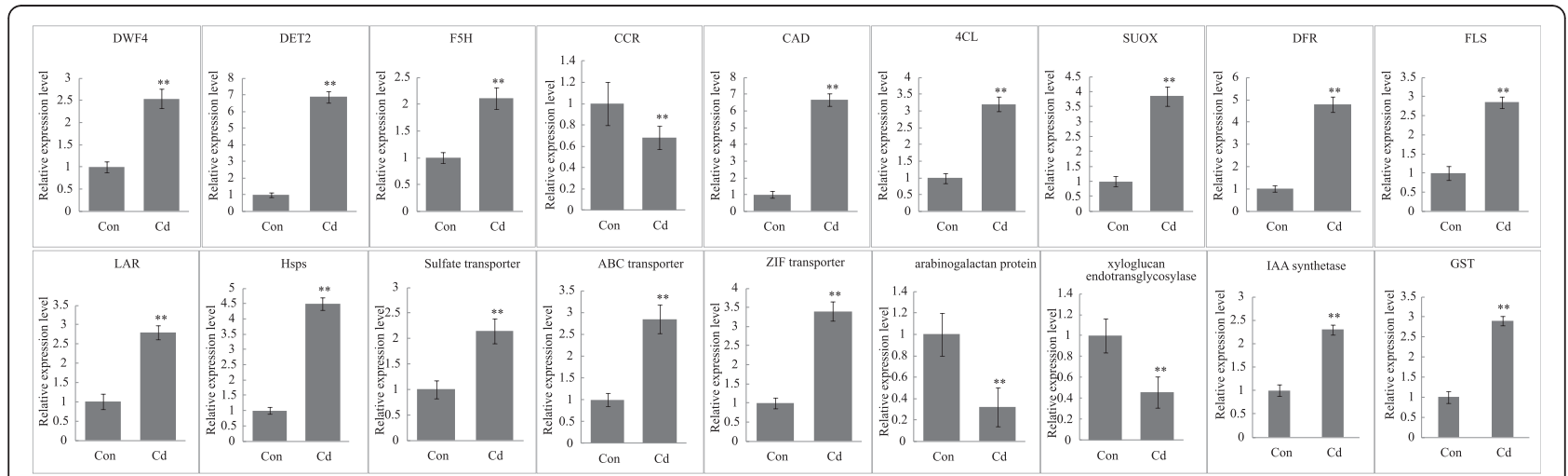

Fig. 7 QRT-PCR analysis of selected genes. The means and standard error values from three independent samples are shown. Asterisks indicate significant differences between non- and Cd-treated leaves (ANOVA; $p<0.01$ ) 


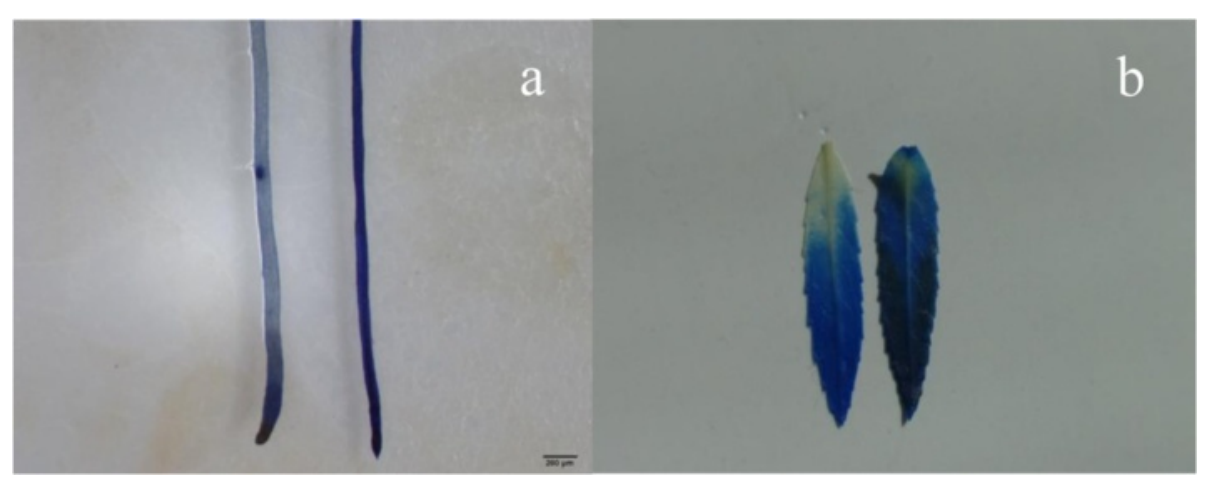

Fig. 8 Callose staining. a Callose in the root of a control (left) and plant cultured in 1/2 MS medium supplemented with $50 \mu \mathrm{M} C \mathrm{Cd}$ for 2 weeks (right). b Callose in the leaf of a control (left) and plant cultured in 1/2 MS medium supplemented with $50 \mu \mathrm{M}$ Cd for 2 weeks (right)

has been reported in several plants when exposed to heavy metal, including Lemna minor L. [40] and poplar [41]. The induction of genes involved in callose deposition in the cell walls of leaves (Fig. 4c) and roots (Fig. 5e) illustrates that synthesis of callose deposition is a common strategy against stress factor penetration in plants. Indeed, callose was synthesized in both root and leaf following a longer period (2 weeks) of $\mathrm{Cd}$ treatment (Fig. 8). Likewise, differentially expressed genes involved in cell wall thickening were almost all up-regulated in the leaf (Fig. 4d) and root (Fig. 4f); this is consistent with results shown in Fig. 1d. It is more than possible that the cell wall thickening was a result of callose synthesis. Thus, thickening of the cell walls of the cortex is an alternative method to reduce uptake of unwanted metals during the early response to Cd in S. matsudana.

Some zinc finger proteins are demonstrated to be involved in abiotic and biotic stresses. Their zinc finger domains are proposed as mediators for toxic metals. Although these proteins are zinc-dependent, divalent metal residues, such as $\mathrm{Cd}$, lead and copper are able to displace the zinc ion from the domain coordination core [42]. The replacement of zinc by extraneous $\mathrm{Cd}$ may contribute to the down-regulation of zinc finger family genes in the leaf. A previous study has proposed this replacement of zinc as a potential mechanism for uptake of the toxic metal. Cellulose is an essential component of both primary and secondary cell walls of higher plants, it is composed of a polymer of $\beta(1,4)$-linked glucose. Xyloglucan is a major component in hemicellulose of plant cell walls. All cellulose synthase genes and xyloglucan endotransglycosylase genes were down-regulated in the leaf (Additional file 2: Table S11). Therefore, the cellulose and hemicellulose content of plant cell decreased under $\mathrm{Cd}$ stress. These results coincide with the fact that most genes involved in lignin synthesis were induced in response to $\mathrm{Cd}$ stress (Fig. 6). Arabinogalactan

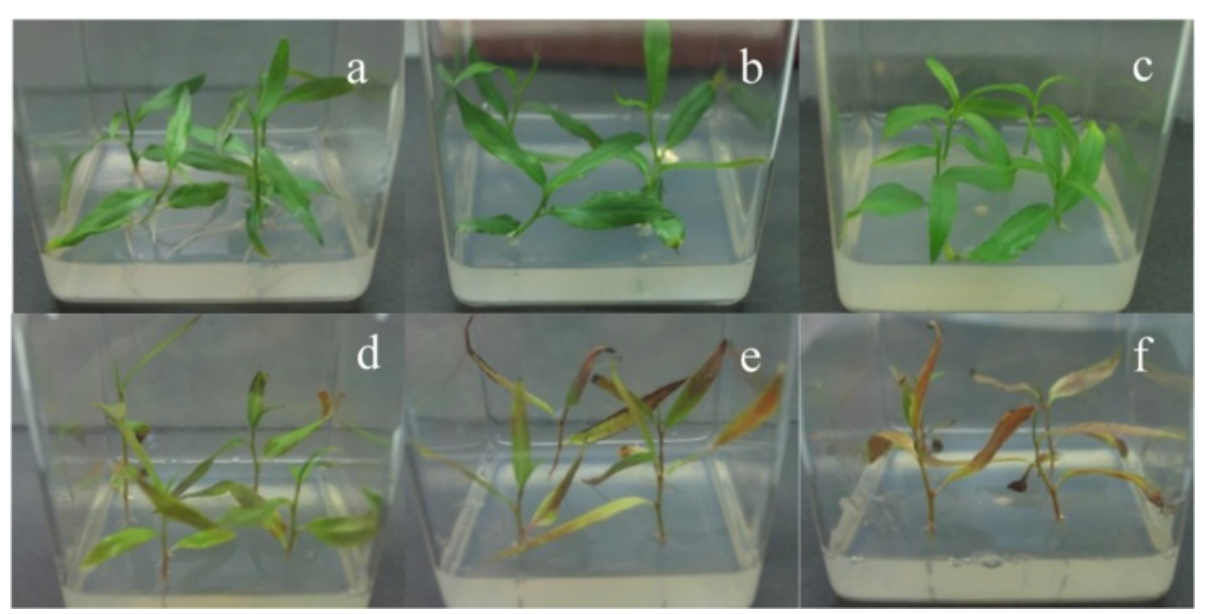

Fig. 9 Effect of brassinazole (Brz) on S. matsudana in response to Cd. a Non-treated plant. b Seedlings cultured in 1/2 MS medium with the addition of $50 \mu \mathrm{M}$ Cd for 2 weeks. c Seedlings cultured in 1/2 MS medium with the addition of $50 \mathrm{nM}$ Brz for 2 weeks. d Seedlings cultured in $1 / 2$ MS medium with the addition of $50 \mu \mathrm{M} \mathrm{Cd}+10 \mathrm{nM}$ Brz for 2 weeks. e Seedlings cultured in 1/2 MS medium with the addition of $50 \mu \mathrm{M}$ $\mathrm{Cd}+20 \mathrm{nM}$ Brz for 2 weeks. $\mathbf{f}$ Seedlings cultured in 1/2 MS medium with the addition of $50 \mu \mathrm{M} \mathrm{Cd}+50 \mathrm{nM}$ Brz for 2 weeks 


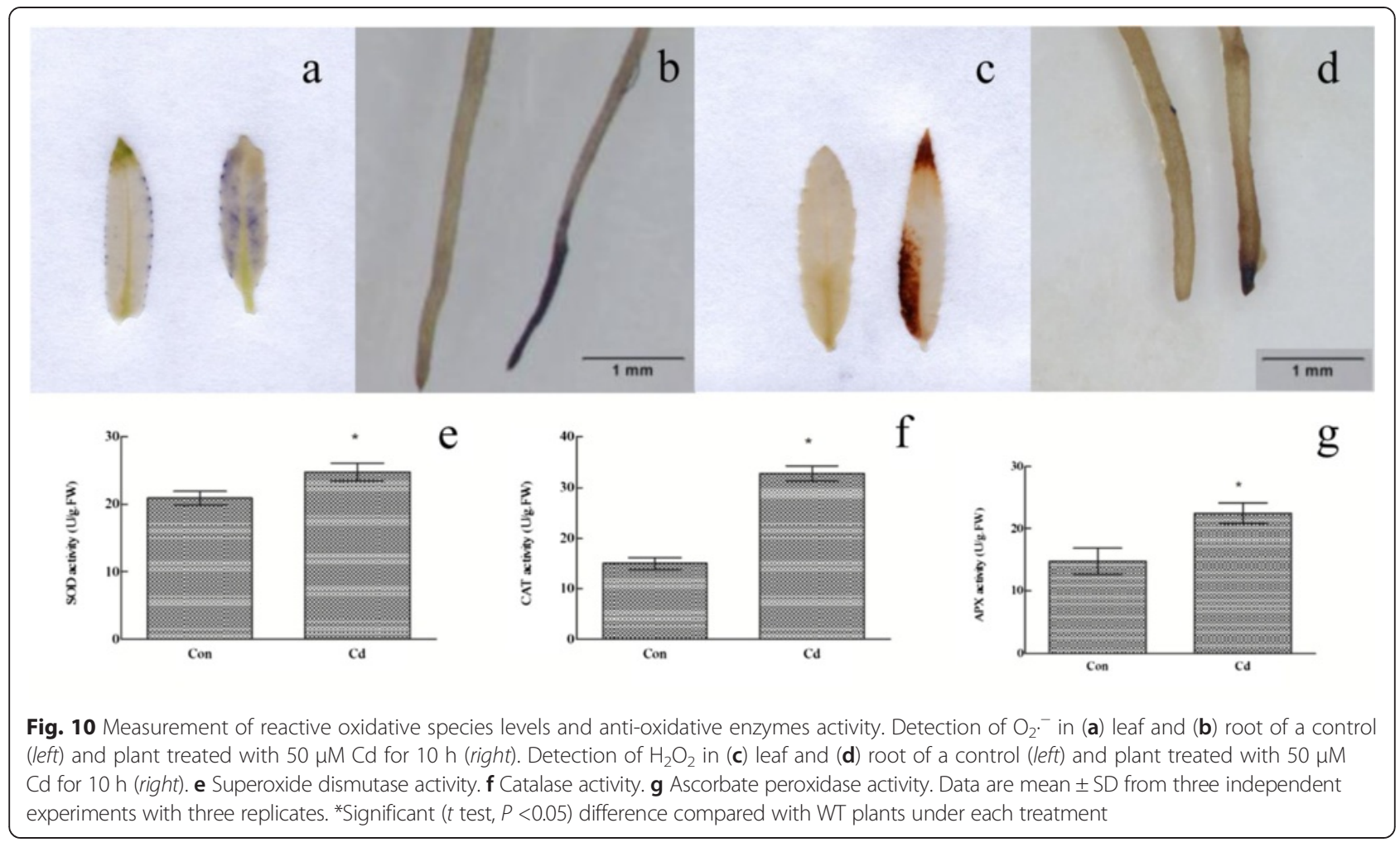

proteins are widely distributed in plant tissues and cells. They have been shown to play a role in the growth and development of higher plants, and especially in root regeneration [43]. The down-regulation of arabinogalactan proteins in the leaf and root (Additional file 2: Table S11) indicates that Cd also affected plant growth, though no morphological differences were observed that could further affect the expression level of arabinogalactan proteins. Additionally, all genes synthesized IAA were down-regulated in the leaf under Cd stress. IAA is a naturally abundant auxin with a regulatory function in plant growth [44]. In this study, IAA synthesis in the root but was inhibited when exposed to $\mathrm{Cd}$. Application of IAA has been proven to increase shoot uptake and phytoextraction efficiency of $\mathrm{Pb}$ both in solution and soil [45]. It is proposed that up regulation of genes synthesize IAA in the root contributed to $\mathrm{Cd}$ phytoextraction from the root but not uptake to the leaf at the early stage of $\mathrm{Cd}$ stress.

Lignin content of plants can be affected by toxic heavy metals [46]. Occurrence of lignin enhancement may play a role in the physical barrier preventing $\mathrm{Cd}$ from entering the plant. Almost all key differentially expressed genes (e.g., PAL, 4CL, CCoAOMT, and $C A D$ ) in the lignin synthesis pathway were up-regulated in the leaf (Fig. 5), suggesting that $\mathrm{Cd}$ treatment induced increased lignin content. A similar result was found in response to $\mathrm{Cd}$ stress in the roots of other plants. When exposed to excess $\mathrm{Cd}$ conditions, lignin biosynthesis genes were upregulated in the roots of Noccaea caerulescens and $A$. thaliana [47]. Cd could also induce synthesis of lignin in the roots of Phragmites australis [48]. Therefore, increased lignin content may contribute to $\mathrm{Cd}$ tolerance in the $S$. matsudana leaf.

\section{Sulphate assimilation and flavonoids metabolisms response to $\mathrm{Cd}$}

Basic metal tolerance mechanisms are similar in various plants. Lin et al. [31] reported that sulphate assimilation, flavonoids, GST, and HSPs play important roles in plant response to heavy metal stress. Similarly, in this study, GST, GSH, and HSP genes were all up-regulated in the leaf (Additional file 2: Table S8), and most genes involved in sulphate assimilation and flavonoid metabolism were also induced, thus indicating a complex Cd-tolerance network for early stress in the leaf. Genes involved in sulphur assimilation are always regulated upon exposure to heavy metals; this is because sulphur metabolism is a key pathway for the synthesis of molecules in response to heavy metals [49]. As it has a high metal binding affinity, GSH is able to work as a chelator [50]. Induction of HSPs in response to heavy metal stress is thought to prevent misfolding of proteins, protein aggregation, and the degradation of proteins under stress [51]. Cadmium stress can induce the expression of several Arabidopsis HSPs, including HSP70s and HSP60s [52]. 


\section{Brassinosteroids and antioxidative enzymes protect $S$. matsudana againt toCd at early stage}

Brassinosteroids are a group of steroidal plant hormones accociated with a number of protective biotic and abiotic stress properties in plants. Previous studies revealed that BRs have the ability to lower metal uptake in plants, probably because of binding of BRs with membrane proteins that enhance metabolic activities by detoxifying heavy metal stresses [53]. In this study, all differentially expressed BR biosynthesis pathway genes in the leaf were up-regulated (Fig. 6). Furthermore, S. matsudana was more sensitive to $\mathrm{Cd}$ when $\mathrm{BR}$ was inhibited by the addition of Brz (Fig. 9d-f), suggesting BR involvement in early response to $\mathrm{Cd}$ in the $S$. matsudana leaf.

A sudden increase in reactive oxygen species leads to extremely toxic products, this invokes an early response to heavy metals, which may lead to lipid peroxidation, enzyme inactivation, and DNA and membrane damage [52]. However, this oxidative burst is required for downstream callose deposition in plants [53]. Cadmium exposure can provoke many different genes involved in scavenging ROS in plants [54]. Several studies have indicated that a high antioxidative capacity is responsible for heavy metal accumulation in plants [55]. The activities of SOD, CAT, and APX were highly activated in both the leaf and root under Cd stress (Fig. 10), suggesting that antioxidative enzymes play a role in the early response of S. matsudana to Cd.

\section{Conclusions}

S. matsudana mainly accumulated $\mathrm{Cd}$ in the vacuole and intercellular space of the root cortex cell. It is noteworthy that the cell wall thickening occurred in the root cells. The transcriptional data was consistent with the result that genes involved in cell wall thickening and defence response by callose deposition in the cell wall were up-regulated in the root. This research provides a new insight into the understanding of $\mathrm{Cd}$ tolerance in woody tree species. Root-to-shoot transportation of $\mathrm{Cd}$ did not occur in the early response to $\mathrm{Cd}$, suggesting that different mechanisms are involved in roots and leaves. Expression profile data revealed that transcriptional expression patterns were distinct in the leaf and root. A complex transcriptional network in the leaf triggers signal transduction, leading to tolerance to cadmium stress. All differentially expressed genes belonging to the BRs biosynthesis pathway were up-regulated in the leaf, suggesting that BRs are involved in the early response to $\mathrm{Cd}$ in the leaf. Additionally, the activation of antioxidative enzyme (SOD, CAT, and APX) activity, both in the root and leaf, suggests the presence of a physiological regulation mechanism to Cd exposure. We systematically investigated tolerance mechanisms in the root and leaf at substructure, transcriptional, and physiological levels. Our study provides useful information for understanding the molecular mechanisms involved in metal absorption, distribution, and transportation, and makes a significant contribution to determining tissue-specific responses to Cd stress.

\section{Availability of supporting data}

The data sets supporting the results of this article are included within the article and additional files.

\section{Additional files}

Additional file 1: Figure S1. Plant screening and growth. (a) Seeds cultured in $100 \mu \mathrm{M} \mathrm{Cd}$ medium for 1 month. (b) Plant growth when exposed to $50 \mu \mathrm{M}$ Cd for 1 month. Figure S2. Measurement of chlorophyll and cadmium. (a) Chlorophyll a, b, and a + b content in the root, stem, and leaf of S. matsudana Koidz. (b) Cd concentration in the root, stem, and leaf treated with $50 \mu \mathrm{M}$ Cd for 1 month. Figure S3.

Characteristics of the similarity search of unigenes against $\mathrm{Nr}$ databases. (a) E-value distribution of BlastX hits for each unigene with an E-value threshold of $10 E^{-5}$. (b) Similarity distribution of the top BLAST hits for each unigene. (c) Species distribution is shown as a percentage of total homologous sequences with an $E$-value of at least $1.0 E^{-5}$. (d) Clusters of orthologous group functional classification of all unigenes. (e) GO classifications of assembled unigenes. Figure S4. Metabolism pathways of sulfur metabolism. Figure S5. Metabolism pathways of flavonoid biosynthesis. (PPT $732 \mathrm{~kb}$ )

Additional file 2: Table S1. Unigene primers used for QRT-PCR analysis. Table S2. Sequencing output statistics. Table S3. Statistics of assembly quality. Table S4. Unigene classification by clusters of orthologous groups function. Table S5. Unigenes assembled by Gene Ontology classification. Table S6. Gene analysis by MapMan in the leaf. Table S7. Gene analysis by MapMan in the root. Table S8. Up-regulated genes in response to cadmium in leaf. Table S9. Up-regulated genes in response to cadmium in root. Table S10. Genes used for cluster analysis. Table S11. Down-regulated genes in response to cadmium in leaf. Table S12. Down-regulated genes in response to cadmium in root. (DOC $751 \mathrm{~kb}$ )

\section{Abbreviations}

APX: Ascorbate peroxidase; BR: Brassinosteroid; Brz: Brassinazole; CAD: Cinnamyl alcohol dehydrogenase; CAT: Catalase; CCOAOMT: Coffee acyl coenzyme A-O-methyl transferase; Cd: Cadmium; 4CL: 4coumarate:coenzyme A ligase; CTAB: Hexadecyltrimethylammonium bromide; DER: Flavanone 4-reductase; DET2: Steroid 5-alpha-reductase; DGE: Digital gene expression; DWF4: Steroid 22-alpha-hydroxylase; F5H: Ferulate-5-Hydroxylase; FLS: Flavonol synthase; GO: Gene ontology; GSH: Glutathione; GST: Glutathione S-transferase gene; HMA: ATPase; HSPs: Heat shock

proteins; IAA: Indole-3-acetic acid; LAR: Leucoanthocyanidin reductase; MTs: Metallothioneins; NGS: Next generation sequencing; PAL: Phenylalanine ammonia-lyase; PCs: Phytochelatins; PGRs: Plant growth regulators; RIN: RNA integration number; SOD: Superoxide dismutase; SUOX: Sulfite oxidase.

\section{Competing interests}

The authors declare that they have no competing interests.

\section{Authors' contributions}

CPY and CHL designed, initiated, and supervised the project. JLY prepared materials and performed experiments and write the manuscript. KL, WZ, $H Z Z, X D C$ and $Y X L$ participated in the genome analysis. All authors read and approved the final manuscript.

\section{Acknowledgement}

This work was supported by the Innovation Project of State Key Laboratory of Tree Genetics and Breeding (Northeast Forestry University) (2013A04), 
science fund of Heilongjiang province (QC2015035) and Heilongjiang postdoctoral fund (LBH-Z14005).

\section{Author details}

${ }^{1}$ State Key Laboratory of Forest Genetics and Tree Breeding, Northeast Forestry University, 26 Hexing Road, Harbin 150040, China. ${ }^{2}$ School of Forestry, Northeast Forestry University, 26 Hexing Road, Harbin 150040, China. ${ }^{3}$ Research Center on Life Sciences and Environmental Sciences, Harbin University of Commerce, Harbin 150076, China.

\section{Received: 21 December 2014 Accepted: 11 September 2015 Published online: 17 September 2015}

\section{References}

1. Salt DE, Smith RD, Raskin I. Phytoremediation. Annu Rev Plant Physiol Plant Mol Biol. 1998:49:643e668.

2. Jabeen R, Ahmad A, labal M. Phytoremediation of heavy metals: physiological and molecular mechanisms. Bot Rev. 2009;75:339-64.

3. Greger M, Landberg T. Use of willow in phytoextraction. Int J Phytoremed. 1999;:1115-23.

4. Witters N, Van Slycken S, Ruttens A, Adriaensen K, Meers E, Meiresonne L, et al. Short-rotation coppice of willow for phytoremediation of a metalcontaminated agricultural area: a sustainability assessment. Bioenerg Res. 2009:2:144-52

5. Rosselli W, Keller C, Boschi K. Phytoextraction capacity of trees growing on a metal contaminated soil. Plant Soil. 2003;256:265-72.

6. Dos Santos Utmazian MN, Wieshammer G, Vega R, Wenzel WW. Hydroponic screening for metal resistance and accumulation of cadmium and zinc in twenty clones of willows and poplars. Environ Pollut. 2007;148:155-65.

7. Cobbett CS. Phytochelatins and their roles in heavy metal detoxification. Plant Physiol. 2000;123:825-32.

8. Guo WJ, Meetam M, Goldsbrough PB. Examining the specific contributions of individual Arabidopsis metallothioneins to copper distribution and metal tolerance. Plant Physiol. 2008;146:1697-706.

9. Lin YF, Aarts MGM. The molecular mechanism of zinc and cadmium stress response in plants. Cell Mol Life Sci. 2012;69:3187-206.

10. Becher M, Talke IN, Krall L, Krämer U. Cross-species microarray transcript profiling reveals high constitutive expression of metal homeostasis genes in shoots of the zinc hyperaccumulator Arabidopsis halleri. Plant J. 2004;37:251-68.

11. Hussain D, Haydon MJ, Wang Y, Wong E, Sherson SM, Young J, et al. P-type ATPase heavy metal transporters with roles in essential zinc homeostasis in Arabidopsis. Plant Cell. 2004;16:1327-39.

12. Wong CKE, Cobbett CS. HMA P-type ATPases are the major mechanism for root-to-shoot Cd translocation in Arabidopsis thaliana. New Phytol. 2009:181:71-8

13. Glenn TC. Field guide to next-generation DNA sequencers. Mol Ecol Resour. 2011;11(5):759-69.

14. Xia J, Wang Q, Jia P, Wang B, Pao W, Zhao Z. NGS catalog: a database of next generation sequencing studies in humans. Hum Mutat. 2012;33:E234155 .

15. Wan LL, Han J, Sang M, Li AF, Wu H, Yin SJ, et al. De Novo transcriptomic analysis of an Oleaginous Microalga: pathway description and gene discovery for production of next-generation biofuels. PLOS ONE. 2012; : 235142

16. Chang L, Chen JJ, Xiao YM, Xia YP. De novo characterization of Lycoris sprengeri transcriptome using Illumina GA II. Afr J Biotechnol. 2011;10:12147-55.

17. Rao G, Sui J, Zeng Y, He C, Duan A, Zhang J. De novo transcriptome and small RNA analysis of two Chinese willow cultivars reveals stress response genes in Salix matsudana. PLoS ONE. 2014;9:e109122.

18. Lundberg M, Boss J, Canbäck B, Liedvogel M, Larson KW, Grahn M, et al. Characterisation of a transcriptome to find sequence differences between two differentially migrating subspecies of the willow warbler Phylloscopus trochilus. BMC Genomics. 2013;14:330.

19. Liu J, Yin T, Ye N, Chen Y, Yin T, Liu M, et al. Transcriptome analysis of the differentially expressed genes in the male and female shrub willows (Salix suchowensis). PLoS ONE. 2013;8:e60181.

20. Yang JL, Yi JS, Yang CP, Li CH. Agrobacterium tumefaciens-mediated genetic transformation of Salix matsudana Koidz. using mature seeds. Tree Physiol. 2013;33:628-39.
21. Murashige T, Skoog F. A revised medium for rapid growth and bioassays with tobacco tissue cultures. Physiol Plantarum. 1962;15:495-7.

22. Jaakola L, Pirttila AM, Halonen M, Hohtola A. Isolation of high quality RNA from bilberry (Vaccinium myrtillus L.) fruit. Mol Biotechnol. 2001;19:201-13.

23. Grabherr MG, Haas BJ, Yassour M, et al. Full-length transcriptome assembly from RNA-Seq data without a reference genome. Nat Biotechnol. 2011;29:644-52.

24. Xu J, Zhu YY, Ge Q, Li YL, Sun JH, Zhang Y, et al. Comparative physiological responses of Solanum nigrum and Solanum torvum to cadmium stress. New Phytol. 2012;196:125-38.

25. Conesa A, Gotz S, Garcia-Gomez JM, Terol J, Talon M, Robles M. Blast2GO: a universal tool for annotation, visualization and analysis in functional genomics research. Bioinformatics. 2005;21:3674-6.

26. Ye J, Fang L, Zheng $\mathrm{H}$, et al. WEGO: a web tool for plotting $\mathrm{GO}$ annotations. Nucleic Acids Res. 2006;34:293-7.

27. Thimm O, Bläsing O, Gibon Y, et al. MAPMAN: a user-driven tool to display genomics data sets onto diagrams of metabolic pathways and other biological processes. Plant J. 2004;37:914-39.

28. Wei HR, Persson S, Mehta T, Srinivasasainagendra V, Chen L, Page GP, et al. Transcriptional coordination of the metabolic network in Arabidopsis. Plant Physiol. 2006;142:762-74.

29. He JL, Li H, Luo J, Ma CF, Li SJ, Qu L, et al. A Transcriptomic Network Underlies Microstructural and Physiological Responses to Cadmium in Populus $\times$ canescens. Plant Physiol. 2013;162:424-39.

30. Guo Z, Ou W, Lu S, Zhong Q. Differential responses of antioxidative system to chilling and drought in four rice cultivars differing in sensitivity. Plant Physiol Bioch. 2006;44:828-36.

31. Lin CY, Trinh NN, Fu SF, Hsiung YC, Chia LC, Lin CW, et al. Comparison of early transcriptome responses to copper and cadmium in rice roots. Plant Mol Biol. 2013;81:507-22.

32. Küpper H, Lombi E, Zhao FJ, McGrath SP. Cellular compartmentation of cadmium and zinc in relation to other elements in the hyperaccumulator Arabidopsis halleri. Planta. 2000;212:75-84.

33. Pence NS, Larsen PB, Ebbs SD, Letham DLD, Lasat MM, Garvin DF, et al. The molecular physiology of heavy metal transport in the $\mathrm{Zn} / \mathrm{Cd}$ hyperaccumulator Thlaspi caerulescens. Proc Natl Acad Sci U S A. 2000;97:4956-60

34. Song WY, Park J, Mendoza-Cózatl DG, et al. Arsenic tolerance in Arabidopsis is mediated by two ABCC-type phytochelatin transporters. Proc Natl Acad Sci U S A. 2010;107:21187-92.

35. Park J, Song WY, Ko D, Eom Y, Hansen TH, Schiller M, et al. The phytochelatin transporters AtABCC1 and AtABCC2 mediate tolerance to cadmium and mercury. Plant J. 2012;69:278-88.

36. Baxter I, Hosmani PS, Rus A, Lahner B, Borevitz JO, Muthukumar B, et al. Root suberin forms an extracellular barrier that affects water relations and mineral nutrition in Arabidopsis. Plos Genet. 2009;5:e1000492.

37. Krzesłowska M. The cell wall in plant cell response to trace metals: polysaccharide remodeling and its role in defense strategy. Acta Physiol Plant. 2011;33:35-51.

38. Zavaliev R, Ueki S, Epel BL, Citovsky V. Biology of callose ( $\beta-1,3-g$ lucan) turnover at plasmodesmata. Protoplasma. 2011;248:117-30.

39. Eticha D, Stass DA, Horst JW. Cell-wall pectin and its degree of methylation in the maize root-apex: significance for genotypic differences in aluminium resistance. Plant Cell Environ. 2005;28:1410-20.

40. Samardakiewicz S, Krzesłowska M, Bilski H, Bartosiewicz R, Woźny A. Is callose a barrier for lead ions entering Lemna minor $\mathrm{L}$. root cells? Protoplasma. 2012;249:347-51.

41. Qin R, Hirano Y, Brunner I. Exudation of organic acid anions from poplar roots after exposure to Al, Cu and Zn. Tree Physiol. 2007;27:313-20.

42. Malgieri G, Palmieri M, Esposito $\mathrm{S}$, et al. Zinc to cadmium replacement in the prokaryotic zinc-finger domain. Metallomics. 2014;6(1):96-104.

43. van Hengel AJ, Barber C, Roberts K. The expression patterns of arabinogalactan proteins AtAGP3O and GLABR2 reveal a role for abscisic acid in the early stages of root epidermal patterning. Plant $\mathrm{J}$. 2004:39:70-83.

44. Pasternak TP, Prinsen E, Ayaydin F, Miskolczi P, Potters G, Asard H, et al. The role of auxin, $\mathrm{pH}$, and stress in the activation of embryogenic cell division in leaf protoplast-derived cells of alfalfa. Plant Physiol. 2002;129:1807-19.

45. Liu D, Li T, Islam E, Jin X, Mahmood Q. Enhancement of lead uptake by hyperaccumulator plant species Sedum alfredii Hance using EDTA and IAA. B Environ Contam Tox. 2007;78:280-3. 
46. Magalhães Silva Moura JC, Bonine CAV, De Oliveira Fernandes Viana J, Dornelas MC, Mazzafera P. Abiotic and biotic stresses and changes in the lignin content and composition in plants. J Integr Plant Biol. 2010;52:36076.

47. van de Mortel JE, Schat H, Moerland PD, Ver Loren van Themaat E, Van der Ent $\mathrm{S}$, Blankestijn $\mathrm{H}$, et al. Expression differences for genes involved in lignin, glutathione and sulfate metabolism in response to cadmium in Arabidopsis thaliana and the related $\mathrm{Zn} / \mathrm{Cd}$-hyperaccumulator Thlaspi caerulescens. Plant Cell Environ. 2008;31:301-24.

48. Ederli L, Reale L, Ferranti F, Pasqualini S. Responses induced by high concentration of cadmium in Phragmites australis roots. Physiol Plantarum. 2004;121:66-74.

49. Mendoza-Cózatl D, Loza-Tavera H, Hernández-Navarro A, Moreno-Sánchez R. Sulfur assimilation and glutathione metabolism under cadmium stress in yeast, protists and plants. FEMS Microbiol Rev. 2005;29:653-71.

50. Paulose B, Chhikara S, Coomey J, Jung HI, Vatamaniuk O, Dhankher OP. A Yglutamyl cyclotransferase protects Arabidopsis plants from heavy metal toxicityby recycling glutamate to maintain glutathione homeostasis. Plant Cell. 2013;25:4580-95.

51. Gupta SC, Sharma A, Mishra M, Mishra RK, Chowdhuri DK. Heat shock proteins in toxicology: how close and how far? Life Sci. 2010;86:377-84.

52. Sarry JE, Kuhn L, Ducruix C, et al. The early responses of Arabidopsis thaliana cells to cadmium exposure explored by protein and metabolite profiling analyses. Proteomics. 2006;6:2180-98.

53. Kaur S, Bhardwaj R. Blockage of Zn-accumulation in seedlings of Brassica campestris L. by 24-epibrassinolide. Keystone Symposium on Plant Responses to Abiotic Stresses. Abstract No. 2004, 216: 64, 19-24.

54. Küpper $\mathrm{H}$, Kochian LV. Transcriptional regulation of metal transport genes and mineral nutrition during acclimatization to cadmium and zinc in the $\mathrm{Cd} / \mathrm{Zn}$ hyperaccumulator, Thlaspi caerulescens (Ganges population). New Phytol. 2010;185:114-29.

55. Schutzendubel A, Polle A. Plant responses to abiotic stresses: heavy metalinduced oxidative stress and protection by mycorrhization. J Exp Bot. 2002;53:1351-65.

\section{Submit your next manuscript to BioMed Central and take full advantage of:}

- Convenient online submission

- Thorough peer review

- No space constraints or color figure charges

- Immediate publication on acceptance

- Inclusion in PubMed, CAS, Scopus and Google Scholar

- Research which is freely available for redistribution 